\title{
ECOGRAPHIC DIAGNOSIS OF FOURNIER GANGRENE - A CASE REPORT
}

\author{
CARLOS EDUARDO L. DE S. CRUZ, JOÃO PEDRO C. CORREIA, PAULA DE O. SILVA, TÁBATA DE O. SILVA, JOBE PETTER
}

\begin{abstract}
Fournier's gangrene is a disease classified as a soft tissue necrotizing infection. In fact, it is a rare and fatal disease. It must be effectively diagnosed within the emergency department and referred for treatment as soon as possible to avoid unfavorable outcomes. The present paper aims to describe a case of Fournier gangrene, showing the usefulness of ultrasonography for the diagnosis and management.
\end{abstract}

\section{KEYWORDS: FOURNIER'S GANGRENE, NECROTIZING FASCIITIS, SONOGRAPHY, SCROTUM, DIABETES MELLITUS, DIABETES COMPLICATIONS.}

\section{INTRODUCTION}

The term Fournier's gangrene (FG) refers to a necrotizing infection that extends to the perianal and genital area ${ }^{1}$. This infection mainly affects men, with only 4 to $10 \%$ of cases in female patients ${ }^{2}$.

This infectious process usually starts in the genitourinary tract, expanding quickly and can cause organic dysfunctions throughout the body ${ }^{3}$. FG is a polymicrobial infection, the main microorganisms found in infectious sites and affected sites are: Escherichia coli, Bacteroides and Streptococci, Staphylococcus, Enterococcus, Clostridium, Pseudomonas and Proteus. This synchronous activity between the anaerobic and aerobic microbiota enables an exponential growth and rapid spread of the infection ${ }^{3}$.

The diagnosis is most often obtained from the physical examination associated with the clinical history, and laboratory and imaging tests can be used in the management of these patients ${ }^{2}$. Despite that, FG can be confused by several scrotal and pelvic pathologies of necrotizing character, thus, imaging exams can be very useful in the management of these patients, since delays in diagnosis result in a mortality of up to $88 \% \%^{4}$.

\section{CASE REPORT}

Male, 54 years old, with pain and testicular edema for three days, associated with fever. He has type 2 diabetes mellitus and arterial hypertension, taking metformin and enalapril. On physical examination with hyperemia and increased scrotal volume associated with crepitation. White blood cell count with 20 thousand total leukocytes. Ultrasound (US) confirmed scrotal and perineal wall edema associated with subcutaneous emphysema, in addition to showing atrophy of the left testicle (figures 1 to 5). The clinical and echographic findings are compatible with Fournier's gangrene, which was confirmed by surgery. He had a good evolution with the use of antibiotic therapy and surgical debridement.

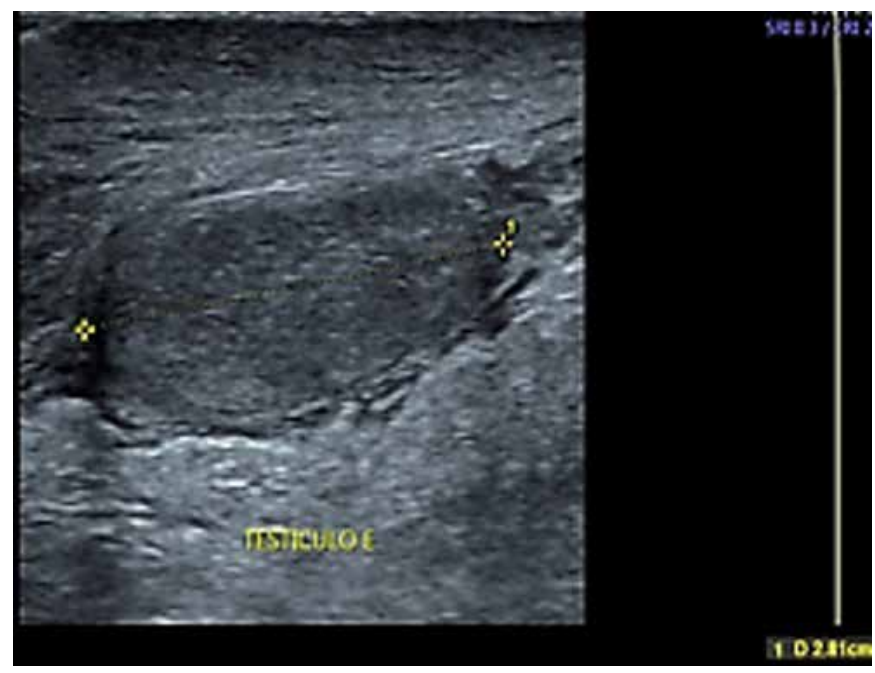

Figure 1: Left testicle with reduced volume and thickening of the scrotal sac walls
1. Centro Universitário do Planalto Central Apparecido dos Santos, Gama, Brasília, DF.

\author{
MAILING ADDRESS \\ JOBE PETTER \\ e-mail: jobe.petter@uniceplac.edu.br
}




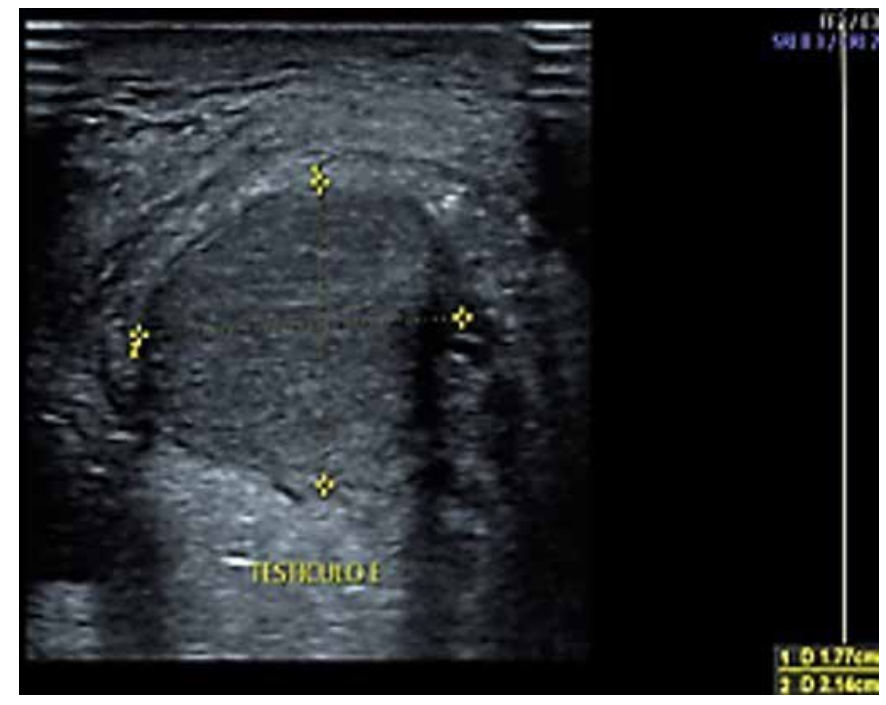

Figure 2: Left testicle with reduced volume and thickening of the scrotal sac walls.

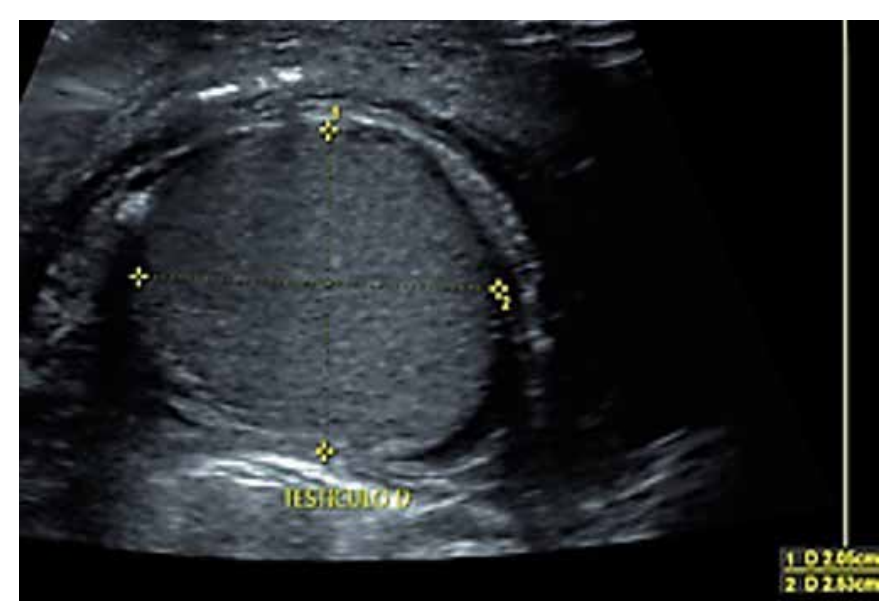

Figure 3: Right testicle without volume changes, scrotal wall edema and subcutaneous emphysema.

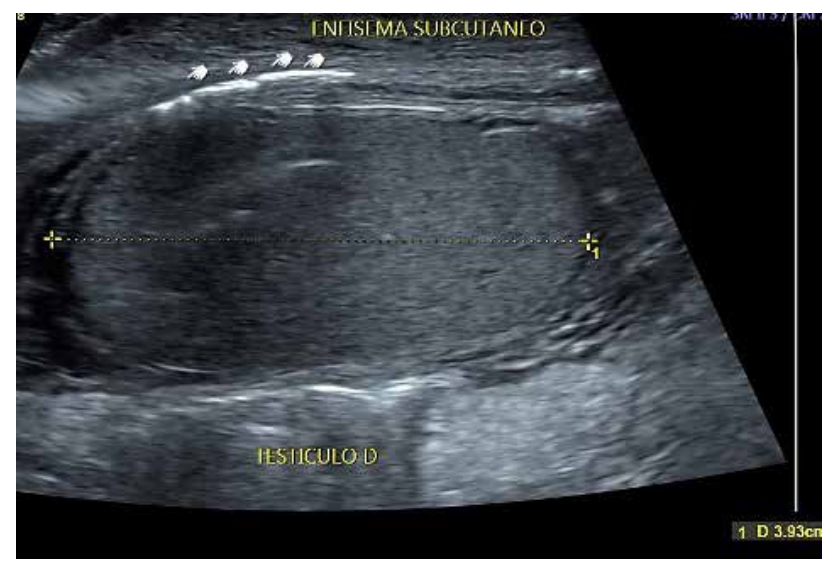

Figure 4: Right testicle without volume changes, scrotal wall edema and subcutaneous emphysema.

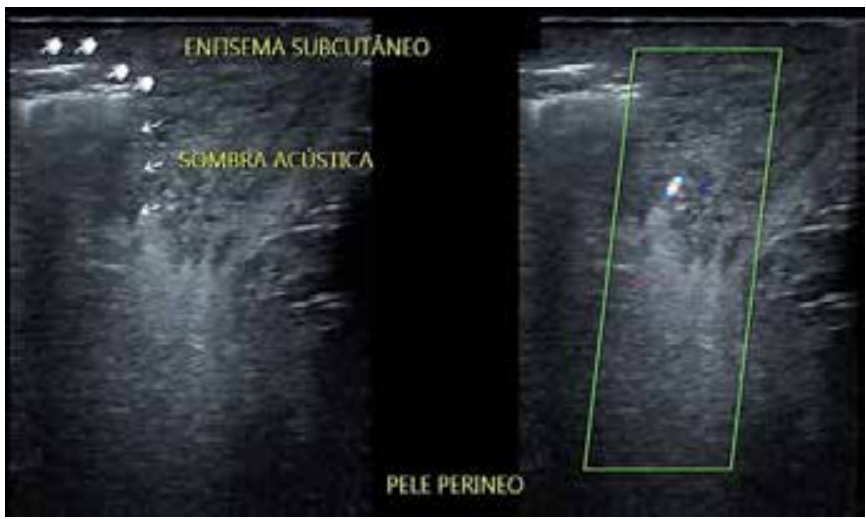

Figure 5: Subcutaneous edema and emphysema (gas) in the perineum

\section{DISCUSSION}

FG presents with fever and lethargy as signs of the prodrome phase of the disease. Symptoms can evolve with pain in the intense region of the genital region, associated with increased sensitivity and signs of edema, which can appear between two and seven days, the final phase of the infection is marked by a subcutaneous cracking and skin darkening that, when evolving it arrives in gangrene and necrosis itself ${ }^{2}$.

It is a condition that mainly affects male patients, between 50 and 60 years of age, and has an average incidence of 1.6 per 100,000 men. Although the diagnosis is essentially clinical, imaging tests are used in many cases as tools for confirming cases with ambiguous clinical features, to investigate an underlying etiology and understand the extent of the infection ${ }^{5}$.

US allows the visualization of soft tissue inflammation, collections, abscesses and subcutaneous emphysema, among the findings we can find perineal tissue thickening caused by inflammation and edema, acoustic shadow caused by subcutaneous gas resulting in the "snow globe" sign and "dirty shadow" caused by the hyperechoic focus. Doppler can be extremely important to assess the vascular supply of the testicle ${ }^{1}$. It is important to differentiate the emphysematous hyperechoic focus, which is external to the testicle, from a possible testicular microlithiasis or tumor calcifications that appear within the testicular area ${ }^{5}$. All of these ultrasound findings demonstrated a specificity of up to $93 \%$ and a maximum sensitivity of $88 \% \%^{1}$.

Compared with other diagnostic modalities, US has a much higher sensitivity than conventional radiography, which is (49\%) and similar specificity (94\%). US performs very similarly to computed tomography (CT) with high sensitivity (88.5\%) and specificity (93\%), evidencing findings such as fluid collections, abscesses, asymmetric thickening of fascias, blurring of adjacent fat and subcutaneous emphyse$\mathrm{ma}^{4}$. CT still manages to assess superficial and deep fascias, allowing the search for differential diagnoses that present with edema, erythema and cellulitis, due to less aggressive entities than $\mathrm{FG}^{5}$. Eventually, the use of magnetic resonance 
imaging (MRI) may be indicated due to its greater sensitivity $(100 \%)$ for the study of soft tissues, which can identify involvement of the deep intermuscular fascia and thickening of fascia structures 5 , although it has a slightly lower sensitivity $(86 \%)^{1}$

\section{CONCLUSION}

Because it is an exam with high availability, accessibility, and does not require preparation or use of contrast, ultrasound is a very efficient technique in the differential diagnosis of acute scrotum. Patients clinically doubtful can benefit from this examination, in addition to speeding up the process of clinical and surgical management.

\section{REFERENCES}

1. Montrief, T; Long, B; Koyfman, A; Auerbach, J. Fournier gangrene: a review for emergency clinicians. The Journal of Emergency Medicine, 2019;57(4): 488-500.

2. Ballard, DH; Mazaheri, P; Raptis, AC; Lubner, GM; Menias, OC; Pickhardt, JP; Mellnick, MV.. Fournier gangrene in men and women: appearance on ct, ultrasound, and mri and what the surgeon wants to know. Canadian Association of Radiologists Journal, 2020;71(1): 30-39.

3. El-Qushayri, AE; Khalaf, KM; Dahy, A; Mahmoud, AR; Benmelouka, AY; Ghozy, S; Mahmoud, MU; Bin-Jumah, M; Alkahtani, S; Abdel-Daim, MM. Fournier's gangrene mortality: a 17-year systematic review and meta-analysis. International Journal of Infectious Diseases, 2020;92: 218-225.

4. Auerbach, J; Bornstein, K; Ramzy, M; Cabrera, J; Montrief, T; Long, B. Fournier gangrene in the emergency department: diagnostic dilemmas, treatments and current perspectives. Open Access Emergency Medicine, 2020;12: 353.

5. Wongwaisayaswan, S; Krishna, S; Haroon, M; Nisha, Y; Sheikh, A. Fournier gangrene: pictorial review. Abdominal Radiology,2020: 1-11. 